\title{
Evaluation of Antibiotic Resistance to Colistin in Nosocomial Infections with Multidrug-Resistant Acinetobacter
}

\author{
Fariba Keramat ${ }^{1}{ }^{\text {iD }}$, Hamid Reza Ghasemi Basir², Abbas Taher ${ }^{3}$, Abbas Moradi ${ }^{4}$, Ali \\ Saadatmand $^{\mathbf{5}}$, Pooria Owji Nejad ${ }^{6, *}$ (iD \\ ${ }^{I}$ Professor, Brucellosis Research Center, Hamadan University of Medical Sciences, Hamadan, Iran \\ 2 Associate Professor, Department of Pathology, School of Medicine, Hamadan University of Medical Sciences, Hamadan, \\ Iran \\ 3 Assistant Professor, Department of Anesthesiology and Intensive Care, School of Medicine, Hamadan University of \\ Medical Sciences, Hamadan, Iran \\ 4 Instructor, Department of Social Medicine, School of Medicine, Hamadan University of Medical Sciences, Hamadan, Iran \\ ${ }^{5}$ MSc in Microbiology, Brucellosis Research Center, Hamadan University of Medical Sciences, Hamadan, Iran \\ ${ }^{6}$ General Practitioner, School of Medicine, Hamadan University of Medical Sciences, Hamadan, Iran \\ * Corresponding Author: Pooria Owji Nejad, School of Medicine, Hamadan University of Medical Sciences, Hamadan, Iran. \\ Email: pooriaojinezhad2020@gmail.com
}

Received: 12.11 .2020

Accepted: 28.01 .2021

How to Cite this Article: Keramat F, Ghasemi Basir HR, Taher A, Moradi A, Saadatmand A, Owji Nejad P. Evaluation of Antibiotic Resistance to Colistin in Nosocomial Infections with Multidrug-Resistant Acinetobacter. Avicenna J Clin Med. 2021; 27(4): 211-216. DOI: $10.29252 /$ ajcm.27.4.211

\section{Abstract}

Background and Objective: Acinetobacter infection is one of the most common nosocomial infections that its antibiotic resistance has increased in recent years. This study aimed to evaluate drug resistance to colistin in nosocomial infections with multidrug-resistant (MDR) Acinetobacter baumannii.

Materials and Methods: This cross-sectional study was performed on 45 blood or body fluid culture samples collected from hospitalized patients at Sina Hospital, Hamadan, Iran, within 2018-2019. The Minimum Inhibitory Concentration (MIC) was determined using E-test trips and disk diffusion method to evaluate the resistance of Acinetobacter baumannii to the antibiotic colistin according to the guidelines of the Clinical and Laboratory Standards Institute. The collected data were analyzed in SPSS software (version 16).

Results: In this study, out of 45 patients, 24 (53.3\%) and 21 (46.7\%) of the subjects were male and female, respectively. The mean age of patients was estimated at $68.0 \pm 15.9$ years. The antibiotic-resistance of samples was determined using the disk diffusion method. Accordingly, all samples were $100 \%$ resistant to ceftriaxone, ceftazidime, ciprofloxacin, cefepime, imipenem, meropenem, ampicillin sulbactam. Out of 45 culture samples examined with MIC, $39(86.7 \%)$ and $6(13.3 \%)$ of samples were sensitive and resistant to colistin, respectively. Based on the results of the disk diffusion method, $21(46.7 \%), 19(42.2 \%)$, and $5(11.1 \%)$ of samples were sensitive, intermediate, and resistant to colistin.

Conclusion: Based on the findings, colistin was effective against multidrugresistant Acinetobacter baumannii and is suggested to be used in cases of Acinetobacter MDR as an effective treatment in combination with other antibiotics.

Keywords: Acinetobacter, Antibiotic Resistance, Colistin 


\section{بررسى مقاومت آنتىبيوتيكى به كليستين در عفونتهاى بيمارستانى با آسينتوباكتر مقاوم به هند دارو}

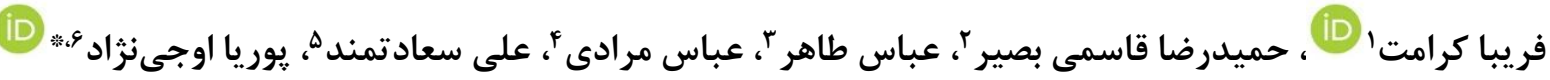

' استاد، مركز تحقيقات بروسلوز، دانشكاه علوم يزشكى همدان، همدان، ايران

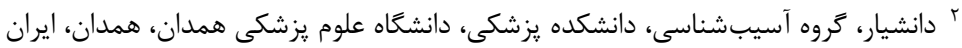

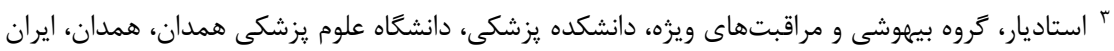

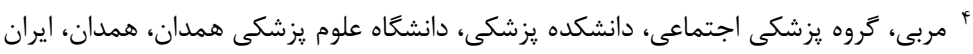

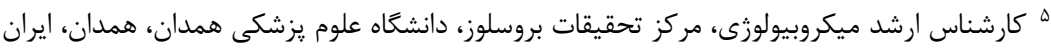

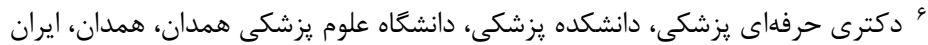
pooriaojinezhad2020@gmail.com : قويسنده مسئول: يوريا اوجىنزاد، دانشكده يزشكى، دانشكاه علوم يزشكى همدان، همدان، ايران. ايميل

\begin{tabular}{|c|c|}
\hline 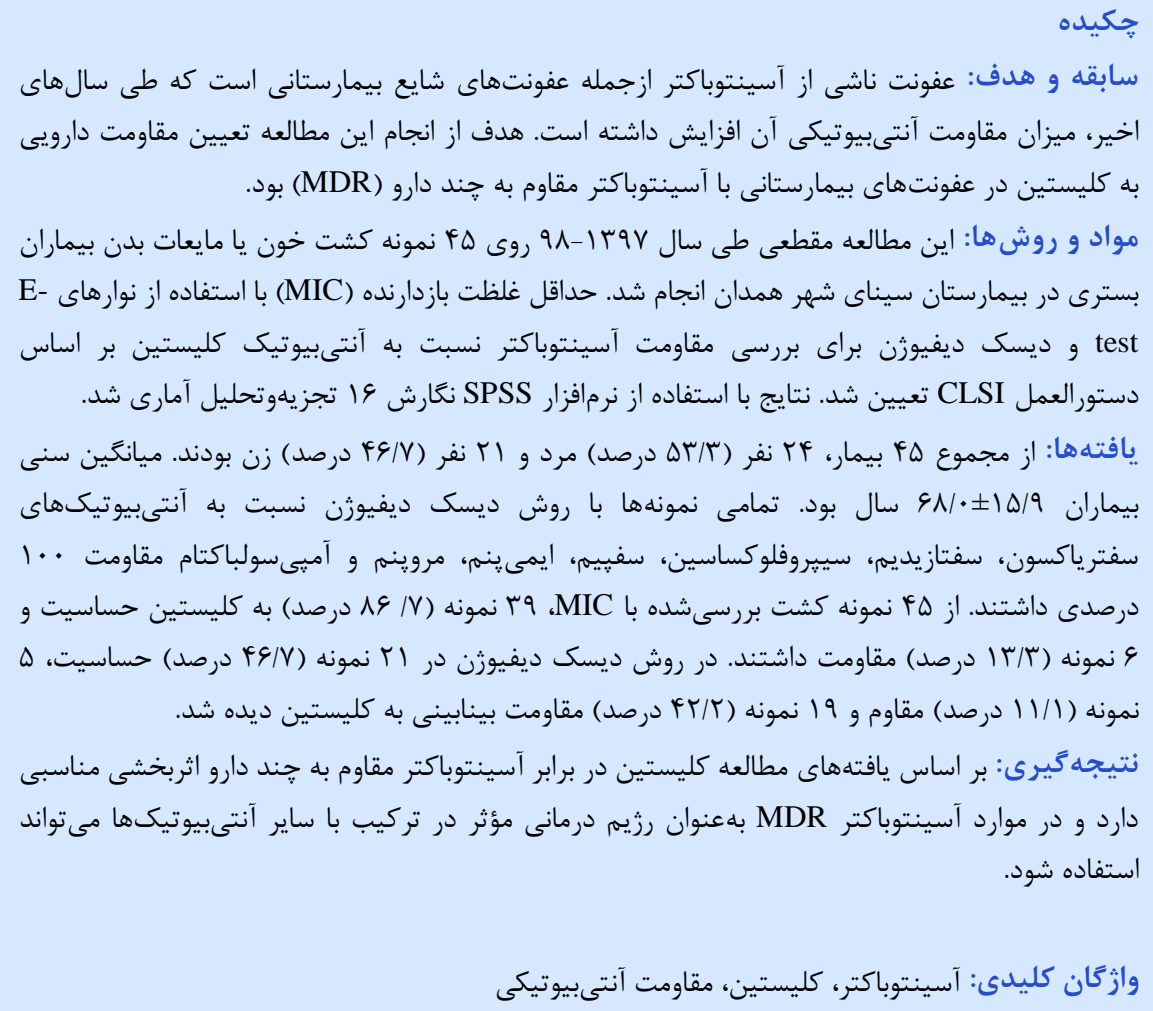 & 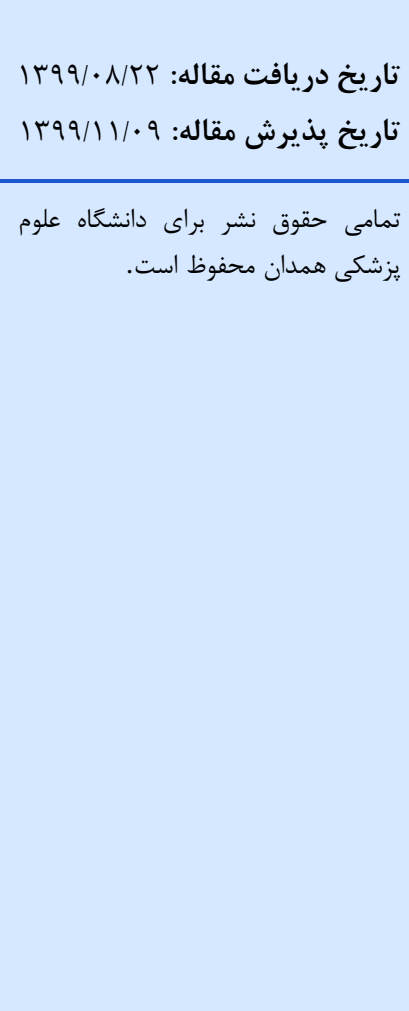 \\
\hline
\end{tabular}

بلندرت عامل عفونتهاى سخت در افراد با سطح ايمنى طبيعى

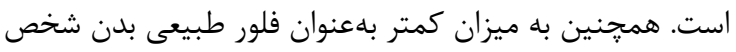

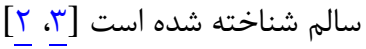

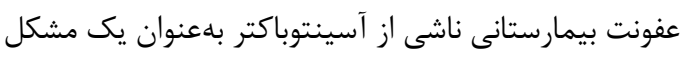

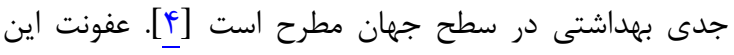

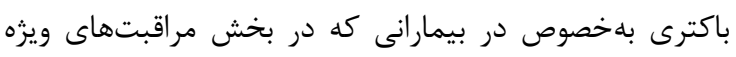

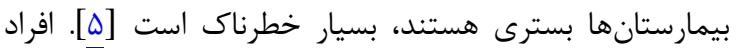

با وجود بيشرفتهاى بسيار در بيشگيرى و درمان بيمارىهاى

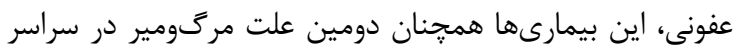

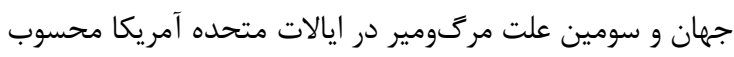

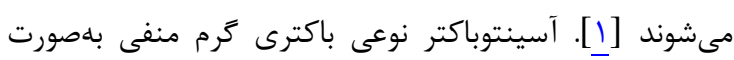

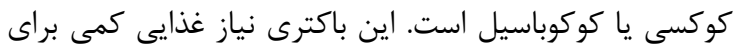

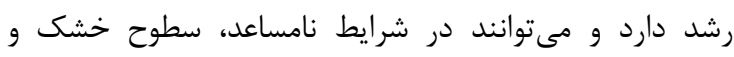
همجنين محيطهاى آبى به مدت طولانى زنده بماند. درد آسينتوباكتر 
(شركت يادتن طب، ايران) آميىسيلين، آمينو مليكوزيدها،

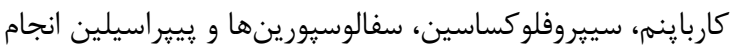

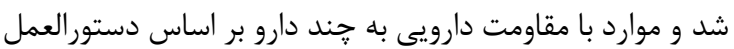

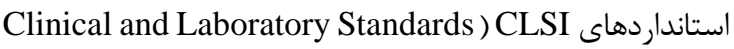
(Institute سيس نمونهها براى انجام آزمايش E-test كليستين وارد

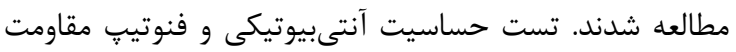

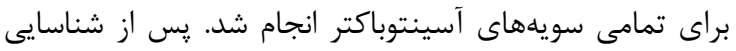

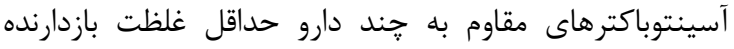
براى (MIC: Minimum Inhibitory Concentration) آنتىبيوتيك كليستين با روش E-test (شركت Liofilchem، براى

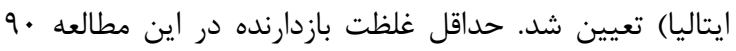

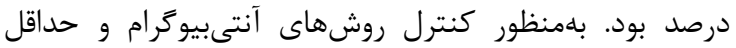

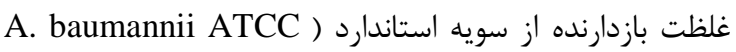

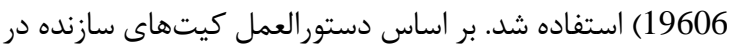

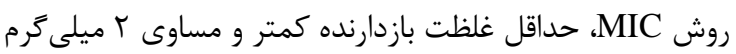
بر ليتر حساس و بيشتر از آن مقاوم و در روش ديسك ديفيوزي

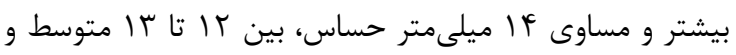
كمتر و مساوى $1 /$ ميلىمتر مقاوم بود.

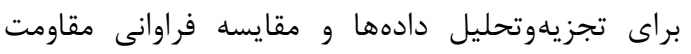

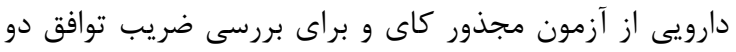
روش ديسك ديفيوزن و حداقل غلظت بازدارنده از ضريب كاري

\section{يافته ها}

درمجموع Q Q كشت مثبت از بيماران وارد مطالعه شدند. TF

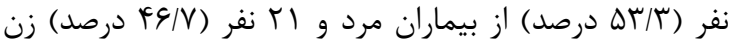

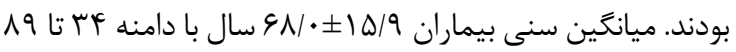

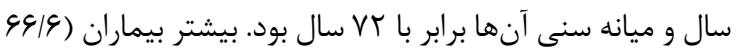

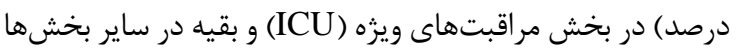
بسترى بودند (جدول ()).

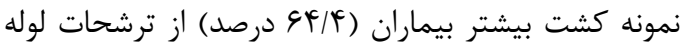

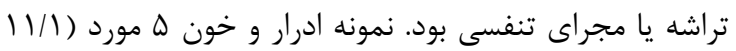

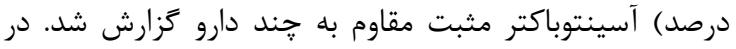

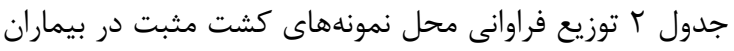
مطالعهشده به تفكيك مشخص شده است.

\begin{tabular}{|c|c|}
\hline فراوانى (درصد) & بخش \\
\hline$(F T / T) 19$ & ICU جنرال \\
\hline$(Y Y / F) \|$ & عفونى ICU \\
\hline$(Y F / F) \|$ & نورولوزى \\
\hline$(\Lambda / 9)^{r}$ & بيمارىهاى عفونى \\
\hline$(1 \cdots) F \Delta$ & جمع \\
\hline
\end{tabular}

مبتلابه بيمارىهاى سيستيك فيبروزيس، نوتروينى يا نقص

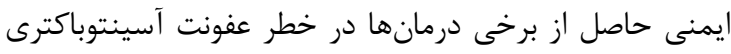

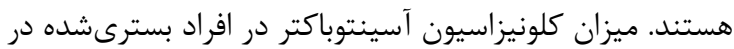

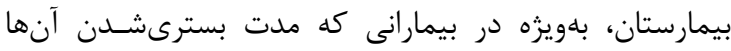

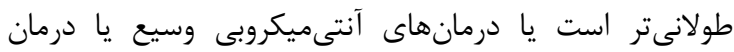

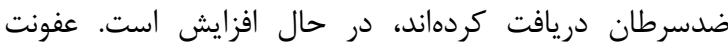

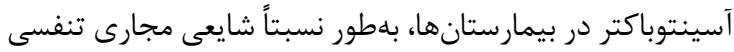

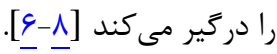
آسينتوباكتر به عوامل ضدميكروبى بسيار مقاوم است كه ده دا.

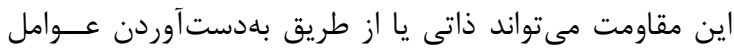

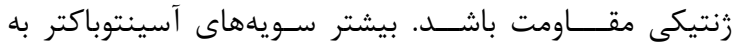

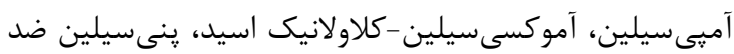

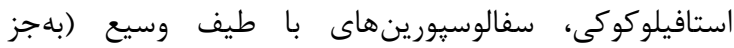

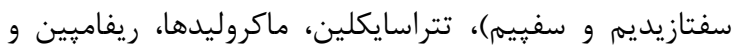

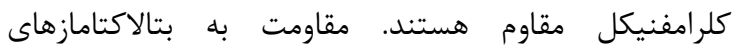
غيركارباينمى در اين باكترى بهطور مقاوم بسيار شايعى با توليد

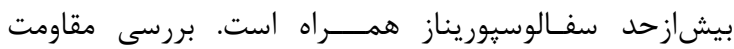

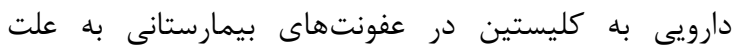

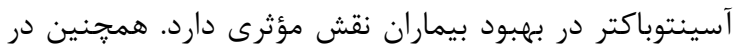

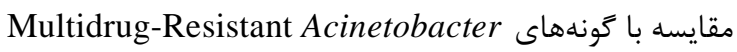
كارايى بهترى دارند [9] (MDR) baumannii كليستين سولفات نوعى آنتىبيوتيك مؤثر بهويزه براى درمان

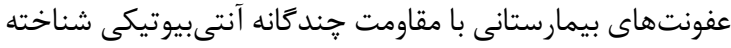

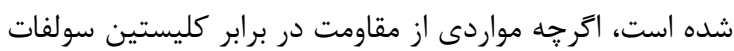

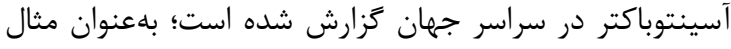

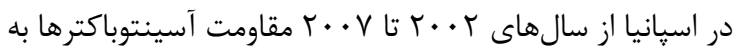
ميزان ها درصد افزايش يافته است، درحالى كه ميزان مقاومت ضدميكروبى در كشورهاى درحالتوسعه مثل ايران، بهطور قابل دئل

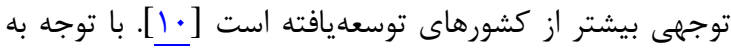

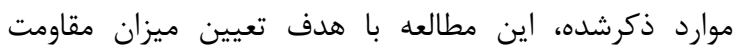
آنتىبيوتيكى به كليستين در عفونتهاى بيمارستانى آسينتوباكتر مقاوم به جند دارو انجام شد.

مواد و روشها

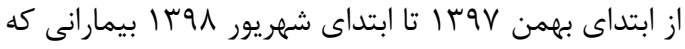

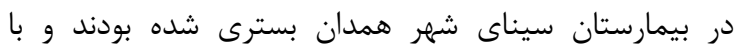

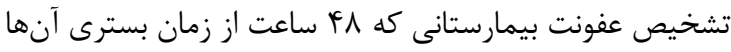

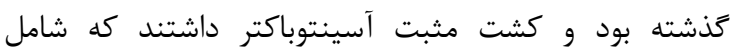
نمونه هاى خون، ادرار، ترشحات ريوى، يلور و CSF بود، وارد اين

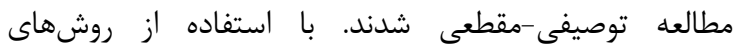

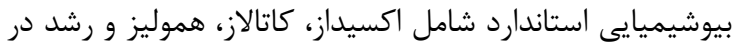
محيطهاى افتراقى خالصسازى و جداسازى باكترى انجام شد.

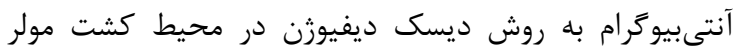

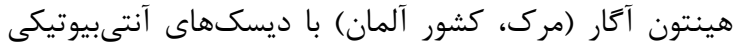


(به كليستين حساسيت و 4 نمونه (ץ/V)

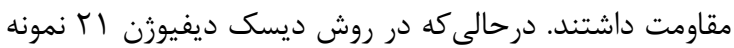

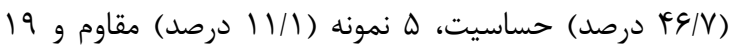

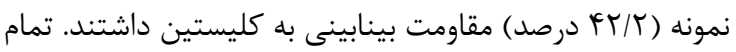

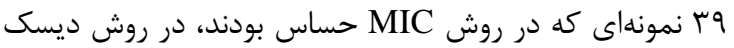

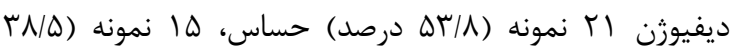

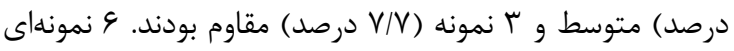

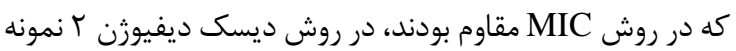

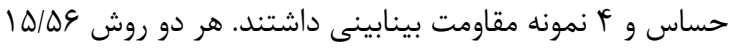

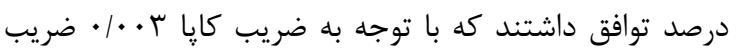

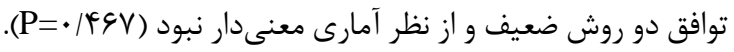

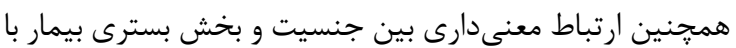

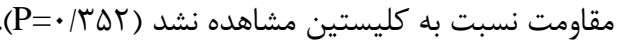

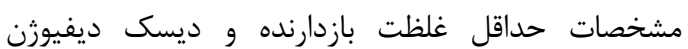
كليستين به تفكيك در جدول ب آمده است.
جدول r: توزيع فراوانى بيماران مطالعهشده به تفكيك نوع نمونهاى

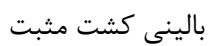

\begin{tabular}{|c|c|}
\hline فراوانى (درصد) & نوع نمونه \\
\hline$(q \mathcal{F} / \boldsymbol{F}) \Gamma q$ & تراشه، خلط \\
\hline$(\mid \mu / \mu) \varphi$ & ترشحات زخم \\
\hline$(11 / 1) \Delta$ & ادرار \\
\hline$(11 / 1) \Delta$ & خون \\
\hline$(1 \cdots) \& \Delta$ & جمع \\
\hline
\end{tabular}

در بررسى آنتىبيوگرام با روش ديسك ديفيوزن تمام

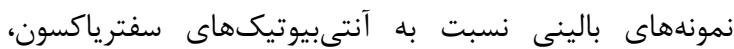
سفتازيديم، سيروفلوكساسين، سفييم، ايمى ينهم، مروينم،

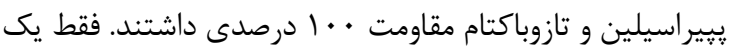

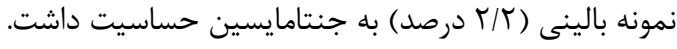

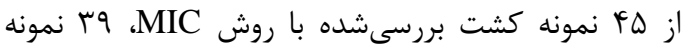

جدول با: مشخصات حداقل غلظت بازدارنده (MIC) و ديسك ديفيوزن كليستين

\begin{tabular}{|c|c|c|c|c|c|}
\hline بيشينه & كمينه & ميانه & انحراف معيار & ميانكَين & \\
\hline$\wedge$ & $\cdot 10$ & $1 / \Delta$ & $1 / K F$ & I/Ar mg/l & MIC (E-test) \\
\hline 19 & 1. & r & $r / \cdot \Delta$ & $14 / 99 \mathrm{~mm}$ & ديسك ديفيوزن \\
\hline
\end{tabular}

ديفيوزن) باشد.

در يك تحقيق ديگر كه صفدرى و همكاران انجام دادند، از

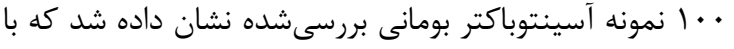

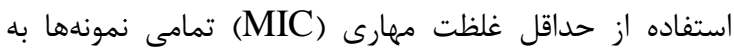

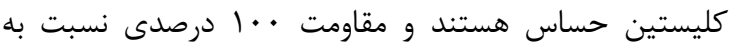

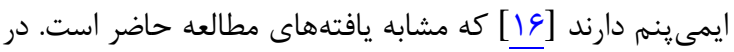

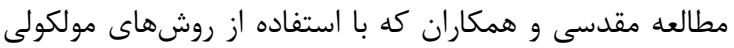

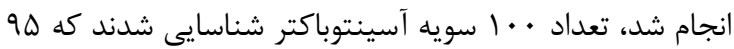

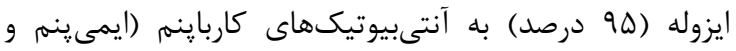
مروينم) مقاومت داشتند [IV] همجنين در مطالعه Angoti و همكاران مقاومت در برابر

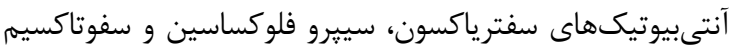

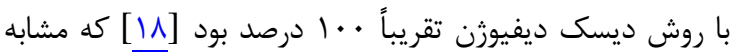

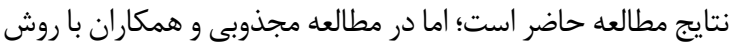

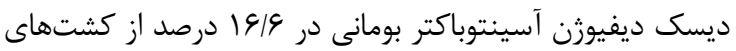
عفونتهاى بيمارستانى مقاوم به جند دارو يافت شد كه ده شيون

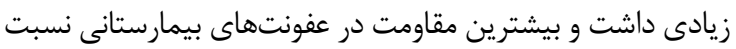

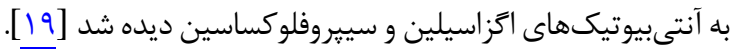
در ساير مطالعات انجامشده در كشورهاى مختلف دين نيز

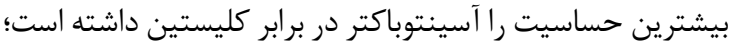

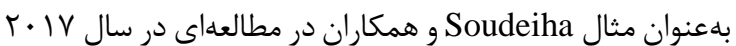

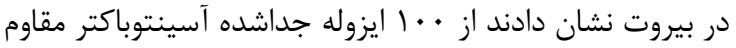

عفونت بيمارستانى ناشى از آسينتوباكتر به يك مشكل جدى

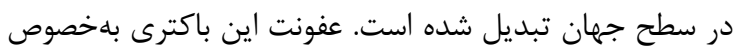

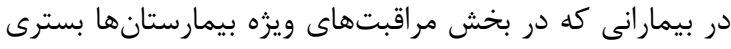

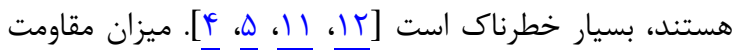

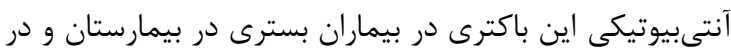

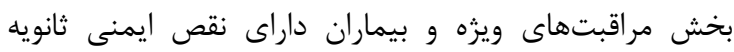

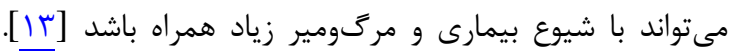

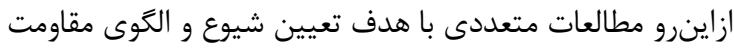

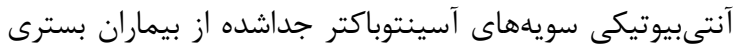
در بيمارستانهاى مختلف كشور و در نقاط مختلف انجام شده

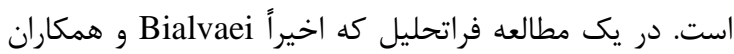

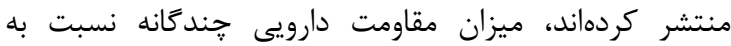

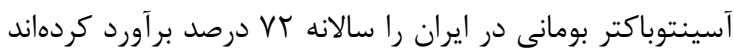

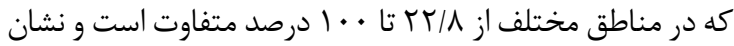

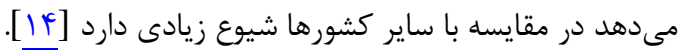

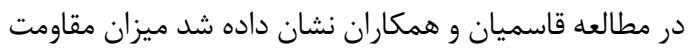

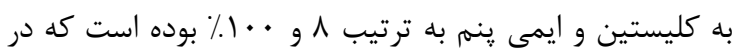

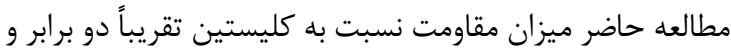

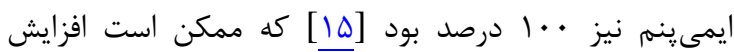
مقاومت مطالعه حاضر با يزوهش ذكرشده به دليل زمان انجام اندام

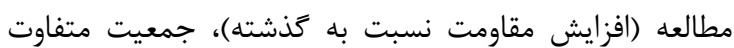

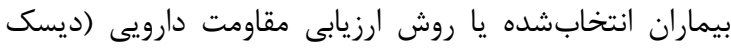




$$
\text { استفاده شود كه اثر سينرزيسم دارند. }
$$

\section{تشكر و قلر قاذى}

اين مقاله بركرفته از ياياننامه دوره دكترى حرفهاى يزشكى

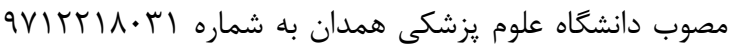

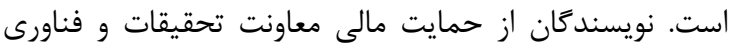
دانشعاه و تمامى افرادى كه در مراحل مختلف اين ماند مطالعه ماند صميمانه همكارى و مشاركت داشتند، تشكر مى كنيند.

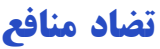
بين نتايج مطالعه و منافع نويسندكان تعارضى وجود ندارد.

ملاحظات اخلاقى

اين مطالعه از كميته اخلاق دانشگاه علوم يزشكى همدان با شناسه IR.UMSHA.REC.1397.972 تأييديه دارد.

\section{سهم نويسنلكَان}

نويسنده اول (يزوهشكر اصلى): طراحى يروزةه و ويرايش

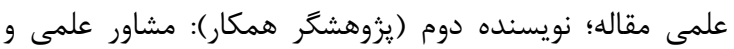

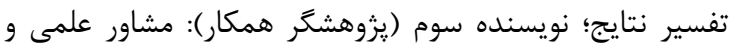
تدوين بخش بحث؛ نويسنده ههارم (يزوهشكر همكار): روششناسى و تحليلكر آمارى؛ نويسنده ينجم (يزوهشكَ همكار):

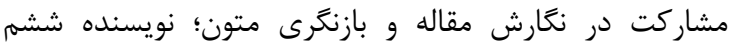

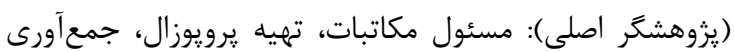
نمونهها، انجام آزمايش ها و نعارش مقاله.

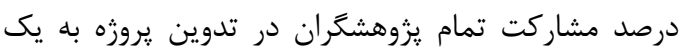
ميزان و برابر بوده است.

\section{حمايت مالى}

اين طرح از سوى معاونت تحقيقات و فناورى دانشعاه علوم

$$
\text { يزشكى همدان حمايت مالى شده است. }
$$

\section{REFERENCES}

1. Fauci AS. Infectious diseases: considerations for the 21st century. Clin Infect Dis. 2001;32(5):675-85. PMID: 11229834 DOI: $10.1086 / 319235$

2. Peleg AY, Seifert H, Paterson DL. Acinetobacter baumannii: emergence of a successful pathogen. Clin Microbiol Rev. 2008;21(3):538-82. PMID: 18625687 DOI: 10.1128/CMR. 00058-07

3. Howard A, O'Donoghue M, Feeney A, Sleator RD. Acinetobacter baumannii: an emerging opportunistic pathogen. Virulence. 2012;3(3):243-50. PMID: 22546906 DOI: $10.4161 /$ viru. 19700

4. Almasaudi SB. Acinetobacter spp. as nosocomial pathogens: epidemiology and resistance features. Saudi J Biol Sci. 2018;25(3):586-96. PMID: 29686523 DOI: 10.1016/j.sjbs. 2016.02.009

5. Manikal VM, Landman D, Saurina G, Oydna E, Lal H, Quale J. Endemic carbapenem-resistant Acinetobacter species in Brooklyn, New York: citywide prevalence, interinstitutional spread, and relation to antibiotic usage. Clin Infect Dis.
به هُند دارو، تنها يك ايزوله به روش E-test مقاوم بود [•r]. در

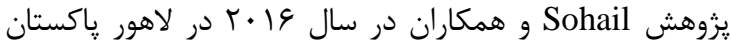
نشان داده شد با روش E-test مقاومت آسينتوباكتر به ايمى ينم

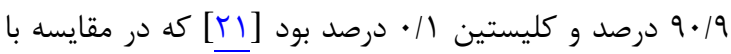

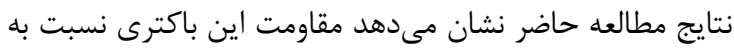

$$
\text { قبل افزايش يافته است. }
$$

Szejbach

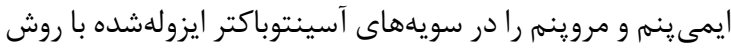

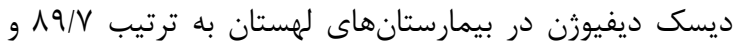

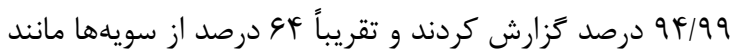
مطالعه حاضر از بخش مراقبتهاى ويزه جمع آورى شده است.

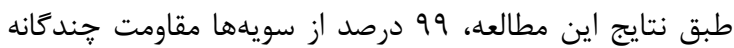
(MDR)

طبق مطالعات انجامشده به نظر مىرسد تجويز نامناسب و

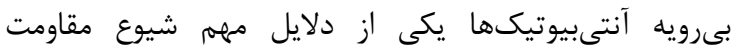

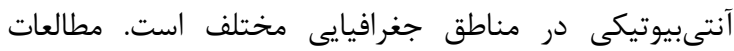

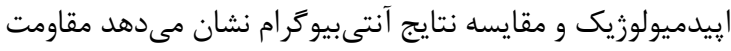
دارويى در نمونهایى بالينى در كشورهاى مختلف و حتى مرئى مراكز

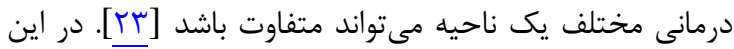

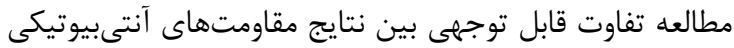

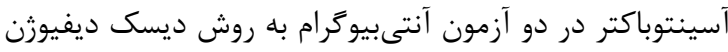

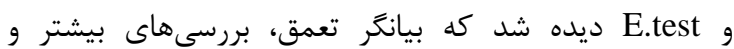

$$
\text { صحتسنجى در اين خصوص است. }
$$

\section{نتيجه تيرى}

يرامون يافتههاى اين مطالعه به نظر مىرسد كليستين

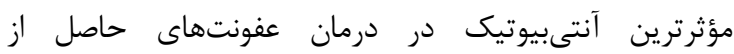

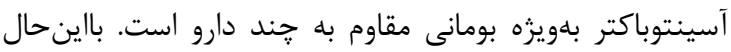
استفاده از كليستين عوارض متعددى ازجمله سميت كليوى دارد.

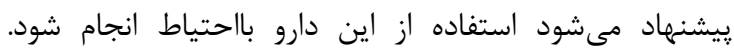

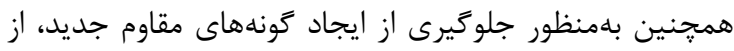
مصرف مونوترايى با اين دارو خوددارى شود و همزمان بان با داروهايى

2000;31(1):101-6. PMID: 10913404 DOI: $10.1086 / 313902$

6. Arroyo LA, Garcia-Curiel A, Pachon-Ibanez ME, Llanos AC, Ruiz M, Pachon J, et al. Reliability of the E-test method for detection of colistin resistance in clinical isolates of Acinetobacter baumannii. J Clin Microbiol. 2005;43(2):9035. PMID: 15695701 DOI: 10.1128/JCM.43.2.903-905.2005

7. De Luca M, Angelino G, Calò Carducci FI, Martino A, Bernardi S, Bernaschi $\mathrm{P}$, et al. Multidrug-resistant Acinetobacter baumannii infection in children. BMJ Case Rep. 2011;2011:bcr0220113807. PMID: 22688471 DOI: 10.1136/bcr.02.2011.3807

8. Wong D, Nielsen TB, Bonomo RA, Pantapalangkoor P, Luna B, Spellberg B. Clinical and pathophysiological overview of Acinetobacter infections: a century of challenges. Clin Microbiol Rev. 2017;30(1):409-47. PMID: 27974412 DOI: 10.1128/CMR.00058-16

9. Shojaei L, Mohammadi M, Beigmohammadi MT, Doomanlou M, Abdollahi A, Feizabadi MM, et al. Clinical response and outcome of pneumonia due to multi-drug 
resistant Acinetobacter baumannii in critically ill patients. Iran J Microbiol. 2016;8(5):288-97. PMID: 28149487

10. Chien ST, Lin CH, Hsueh JC, Li PL, Hsu CH, Chang SH, et al. Mutation of gyrA and parC in clinical isolates of Acinetobacter baumannii and its relationship with antimicrobial drugs resistance in Taiwan. Ann Microbiol. 2009;59(2):369-72. DOI: 10.1007/BF03178341

11. Antunes LC, Visca P, Towner KJ. Acinetobacter baumannii: evolution of a global pathogen. Pathog Dis. 2014;71(3):292301. PMID: 24376225 DOI: 10.1111/2049-632X.12125

12. Howard A, O'Donoghue M, Feeney A, Sleator RD. Acinetobacter baumannii: an emerging opportunistic pathogen. Virulence. 2012;3(3):243-50. PMID: 22546906 DOI: $10.4161 /$ viru. 19700

13. Moradi J, Hashemi FB, Bahador A. Antibiotic resistance of Acinetobacter baumannii in Iran: a systemic review of the published literature. Osong Public Health Res Perspect. 2015;6(2):79-86. PMID: 25938016 DOI: 10.1016/j.phrp. 2014.12.006

14. Bialvaei AZ, Kouhsari E, Salehi-Abargouei A, Amirmozafari $\mathrm{N}$, Ramazanzadeh R, Ghadimi-Daresajini A, et al. Epidemiology of multidrug-resistant Acinetobacter baumannii strains in Iran: a systematic review and meta-analysis. $J$ Chemother. 2017;29(6):327-37. PMID: 28622734 DOI: 10.1080/1120009X.2017.1338377

15. Ghasemian R, Ahanjan M, Fatehi E, Shokri M. Prevalence and antibiotic resistance pattern of acinetobacter isolated from patients admitted in ICUs in Mazandaran, Northern Iran. Global J Health Sci. 2016;8(11):112-9. DOI: 10.5539/gjhs.v8n11p112

16. Safdari H, Maghrouni A, Farsiani H. Study of Imipenem and Colistin resistance rates of isolated Acinetobacter baumannii from hospitalized patients in Imam Reza and Ghaem hospitals of Mashhad through E-test. Iran J Obstet Gynecol Infertil. 2019;21(11):32-6. [Persian]

17. Moghadasi M, Kalantar-Neyestanaki D, Karami-Zarandi M,
Rahdar HA, Jasemi S, Feizabadi MM. Investigation of antimicrobial susceptibility patterns and frequency of bla OXA genes in carbapenem resistant Acinetobacter baumanniistrains. Sci J Kurdistan Univ Med Sci. 2018; 23(5):108-19. [Persian]

18. Angoti G, Godarzi H, Besharat M, Hajizadeh M, Zarringhalam Moghaddam M. Evaluation of antibiotic resistance of clinical Acinetobacter baumannii isolated of Tabriz hospital by disk diffusion and MIC methods. Res Med. 2014;38(2):106-10. [Persian]

19. Majzoobi MM, Pirdehghan A, Rashidian Z, Saadatmand A. Etiologic agents and antibiotic resistance pattern of community- and hospital-acquired infections. Avicenna $J$ Clin Med. 2018;25(1):41-8. DOI: 10.21859/ajcm.25.1.41

20. Soudeiha MAH, Dahdouh EA, Azar E, Sarkis DK, Daoud Z. In vitro evaluation of the colistin-carbapenem combination in clinical isolates of $A$. baumannii using the checkerboard, Etest, and time-kill curve techniques. Front Cell Infect Microbiol. 2017;7:209. PMID: 28596943 DOI: 10.3389/fcimb.2017.00209

21. Sohail M, Rashid A, Aslam B, Waseem M, Shahid M, Akram $\mathrm{M}$, et al. Antimicrobial susceptibility of Acinetobacter clinical isolates and emerging antibiogram trends for nosocomial infection management. Rev Soc Bras Med Trop. 2016;49(3):300-4. PMID: 27384826 DOI: 10.1590/00378682-0111-2016

22. Szejbach A, Mikucka A, Bogiel T, Gospodarek E. Usefulness of phenotypic and genotypic methods for metallo-betalactamases detection in carbapenem-resistant Acinetobacter baumannii strains. Med Sci Monit Basic Res. 2013;19:32-6. PMID: 23333953 DOI: 10.12659/msmbr.883744

23. Safari M, Saidijam M, Bahador A, Jafari R, Alikhani MY. High prevalence of multidrug resistance and metallo-betalactamase (MbetaL) producing Acinetobacter baumannii isolated from patients in ICU wards, Hamadan, Iran. J Res Health Sci. 2013;13(2):162-7. PMID: 24077474 